\section{POSTOPERATIVE TONSILLAR BLEEDING}

ITS SURGical control, With MENTION OF CASES*

\section{LEE COHEN, M.D.} BALTIMORE

The operation on the faucial tonsils at this time may be said to be in a transitional stage from that of incomplete to complete removal. The importance of this subject prompted me to make known some of my ideas and experiences connected with the operation. My first intention was to discuss the entire subject in a general way, and the ideas of a number of the leaders in this Section were asked for in a circular letter addressed to them. I desire here to express my appreciation of their hearty and prompt replies. Our Executive Committee, realizing the magnitude and great importance of the tonsil operation, very wisely decided that a symposium would best serve the purpose of bringing forth a comprehensive and general discussion. I have, therefore, the honor of saying a few words about postoperative tonsillar bleeding.

Hemorrhage from the removal of the faucial tonsils varies greatly, the primary bleeding when all goes favorably amounting to less than an ounce. In some cases, however, the bleeding reaches alarming proportions. The term "alarming proportions" is difficult to define, since a loss of blood which some operators would look on with indifference might cause others great concern. Again a loss of from four to six ounces of blood in some cases might be considered alarming if the patient were frail or young, whereas in a strong, robust individual a loss of this amount of blood could work no material harm other than prolonging convalescence.

Generally speaking, female patients beyond puberty bear loss of blood better than males because of their propensity for more rapid blood-making. When confronted with a freely spurting vessel it is impossible to determine how great may be the loss of blood should it not quickly and effectualiy be controlled. I can recall my feeling of dismay when first brought face to face with a real bleeding of this kind, but that first case of extreme bleeding proved to be a blessing in disguise, for it forced me to adopt measures whereby I may now feel reasonably secure from any very serious effects of tonsillar bleeding.

I am told by such men as Welty, Stucky, Richards, Robertson, 'Todd ${ }^{1}$ and others that the loss of blood following a complete removal of the tonsil in its capsule is less than after the old method of tonsillotomy with the guillotine. On the other hand, Jackson, Thomas, Vaughan and others, ${ }^{2}$ while advocating such complete removal, claim that the loss of blood is greater therefrom.

A fact worthy of note is that, of the 54 cases of alarming bleeding tabulated by $\mathrm{Smith}^{2}$ and Wright, ${ }^{3}$ the tonsillotome in some one of its many forms was employed in 34; and it was also used to remove the tonsils in at least 3 of the 6 fatal cases found by them in the literature from 1868 to 1904, the method of removal in the other 3 fatal cases not having been mentioned. In the 4 more recent fatal cases, reports of which I have been able to collect, the tonsillotome only was employed.

* Read in the Section on Laryngology and Otology of the Ameri. can Medical Association, at the Sixtieth Annual Session, held at Atlantle City, June, 1909 .

1. Persoaal conmunteations in reply ta questions.

2. Smith, Harmon: Alarming Hemorrhage Following Tonsillotomy ivis Larygoscope, 1904, p. 121.

3. Wright, Jonathan: Ifemorrhage After Amygdalotomy . . . .
Now York Med. Joun.. 1s9o, lif, 234.
My experience has been that there is a greater tendency to bleed in tonsillectomy than in tonsillotomy, because, in the former, vessels are cut before they subdivide into the terminal filaments and nearer to the source of the large arteries from which they are given off. But I have adopted the complete removal because of the better results thereby obtained, and in performing this operation I have learned how bleeding can be controlled, so that I now feel that the loss of blood from my complete operation is generally much less than it formerly was in performing tonsillotomy.

Two of my cases which I wish to report will illustrate clearly the difference between the old and nonsurgical method of controlling hemorrhage and the more recent and effectual one.

CASE 1.-Operation.-A. K., a healthy woman, aged 23, was operated on by me in my office on Jan. 28 , 1908, at 4 p. m., under local anesthesia. Both tonsils, which were perhaps the largest I have ever seen, were removed en masse with the knife and vulsellum. Bleeding from both sides at the time of the operation was quite profuse, the bleeding on the left side being effectually stilled by pressure with cotton soaked in Monsell's solution. On the right side I was obliged to use Boetcher's hemostat.

Postoperative Heinorrhages.-The patient was removed from my office to the Hebrew Hospital in the evening with the clamp still in position. The hemostat was removed at 10 p. m., the cotton pledget being left in position for nearly three days. No bleeding on removal of cotton. The following, or fourth day, patient left hospital. Nine days after the operation, at midnight, there was a slight bleeding from the right sile, this being easily controlded by the use of ice internally and externally. There was no further loss of blood until the following afternoon at $3: 30$, when it was again necessary to make use of the pressure hemostat. The patient was then sent back to the hospital, and on attempting to remove the clamp at 11 p. m., hemorrhage recurred, making it necessary to replace it. The following morning. February 8 , at 2 a. m., a slight bleeding was again noticed, but it was controlled easily by pressure and the use of ice. At 4 o'clock the same day there was again a slight loss of blood, at which time a heavy silk suture was passed deeply through the upper portion of the tonsillar pillars, over the point from which the bleeding seemed to come. For the following twenty-four hours there was no bleeding, and the patient's condition was very satisfactory. Late the next afternoon, February 9, twelve days after the operation, very active hemorrhage commenced, in spite of the suture. Mere pressure had no effect, so the hemostat was again placed in position, bleeding being controlled after a few minutes. At 7 p. m., the clamp slipped, and before it could be replaced a pus basinful of blood was lost.

Control of Hemorrhage.-The patient now being quite weak, we realized that some very radical measures must be adopted at once to avert a fatal issue. She was therefore placed on the operating table at $7: 30 \mathrm{p}$. m., firm pressure being made over the common carotid artery to prevent further bleeding. A roll of iodoform gauze about the size of the tonsil removed, saturated with 1 to 1,000 adrenalin chlorid solution was placed in the tonsillar fossa, and firmly held with a large Kelly clamp by an assistant. A continuous suture was then placed in the pillars of the fauces from the soft palate down to the base of the tongue, a curved Hagedorn needle, placed at a right angle in a plain needle-holder, being used for this purpose. No anesthetic was used for this operation, on account of the weak state of the patient. The time consumed in the work was about half an hour. The pulse was small -about 160 to the minute, and the general condition of the patient was very bad. Two salt infusions of about a pint each were given, one at once and another during the night. There was not a drop of blood lost from this time on. The suture was removed four days later and the gauze pledget allowed to remain one day longer. The tonsillar fossa on re- 
moval of the gauze luoked vely clean, and the patient steadily improved, leaving the hospital in excellent condition on February 21, fifteen days after her last admission.

The lessons Iearned from this case have been most valuable: First, I believe the secondary bleeding was directly caused by the sloughing process following the primary use of Monsell's solution in the tonsillar fossa. I would never again sanction the use of this agent in controlling hemorrhage from the tonsillar region. Second, by permitting repeated recurrences of the bleeding over so long a period of time the patient's life was almost lost. In a similar case I would adopt radical measures at once. Third, had the primary bleeding in this case been managed in the same surgical manner that we employ to-day, we should have been spared all our trouble and anxiety and the patient the danger and discomfort to which she was subjected.

A very interesting case, and one which was managed in a manner somewhat like my own but which ended fatally, has been reported by Damianos and Heimann of Vienna. There are many points in this case worthy of note, and I therefore take the liberty of "giving it in detail :

CASE 2.-The patient, a strong, robust man, aged 23, was operated on in one of the dispensaries, with Fahnstock's ton. sillotome, on the afternoon of Oct. 9, 1901. An hour and a half later he was brought into the Vienna surgical clinic bleeding profusely from what appeared to be an artery of large caliber. Digital pressure, within and without, over a period of an hour and a quarter, controlled the hemorrhage for about an hour. When it recurred a Mikulicz-Störk com. pression clamp was applied until the following morning. No further bleeding occurred for three days. On October 13 it was again necessary to apply the clamp to stop bleeding. Removal of the clamp twenty-four hours later, the 14th, was followed by more bleeding, necessitating its further immediate use. No further hemorrhage occurred until the 16thtwo days later-when it was once again necessary to make use of the compression clamp. Its removal twenty-four hours later was not followed by bleeding, but there were signs of sloughing at the points where the pressure had been too continuously made by the clamp. A fistula leading from the throat within, through the skin, permitting fluids to escape on swallowing, made its appearance on the 18th, a day later. On the night of the $22 \mathrm{~d}$, following an intense paroxysm of coughing, a profuse hemorrhage occurred, the patient losing almost a liter of blood within a few minutes. This was controlled by prolonged digital pressure, but the patient sustained another, though smaller, loss of blood during the night. The following morning, the $23 \mathrm{~d}$, the common carotid artery was ligated, but the patient died at 4:30 o'clock in the afternoon, sixteen days after the operation, not having been able to withstand the great loss of blood. Autopsy showed that a small artery arching off from the external maxillary, and running directly into the base of the tonsil, had been severed. A sound could be passed through this vessel from the external maxillary artery to the point in the tonsillar base where it had been cut.

It is clear in my mind that had this bleeding vessel been caught with the artery forceps and ligated with catgut or silk before the loss of blood was so great, the patient's life could have been saved.

To illustrate how such serious bleedings can be averted when the proper measures are used to control primary bleeding, I shall now report a more recent case occurring in one of my patients at the Hebrew Hospital:

CAsE 3.-Operation.-M. H., a man aged 36, height 5 feet, waist measure 45 inches and weight 185 pounds (all conditions promising for much bleeding), was operated on by me

4. Damianos and Hermann: Tödliche Nachblutung nach Tonsil4. Damianos and Hermann: Tödliche Nachblutung nach
lotomie . . . Wien. kitin. Wchnschr., 1902, p. 225. under local anesthesia, Dec. 31,1908 , at 4 p. m. There was no difficulty in the removal of both tonsils en masse in their capsules, with the knife and vulsellum, without injury to thepillars of the fauces or exposure of muscle tissue. There was practically no primary bleeding, and the patient was required to keep in an upright position for several hours.

Postoperative Hemorrhage.-There was but the occasional expectoration of blood-stained saliva until about 9 o'clock in the evening, when the patient began to bleed profusely. $\mathrm{He}$ was then taken to the operating room and placed on the table. Bleeding from both tonsillar fossie was found, more profusely from the right, however. A large spurting artery situated deep in the fossa of the right side, near the base of the anterior pillar, was pumping a steady stream across the opposite side of the throat. The bleeding was so profuse that pressure with several sponges seemed to have but little effect.

Control of Hemorrhage.-This vessel was then caught with the Jackson hemostat as quickly as possible and tied with catgut. There was another bleeding vessel of considerable size situated in the supratonsillar fossa of the same side, and this was also clamped and ligated. The patient lost perhaps in all about eight ounces of blood. Though this controlled the major part of the bleeding, there was still a tendency to ooze. The cause for this was soon found and one more artery of small size, situated deeply about the middle of the right posterior pillar, was caught and tied, also two small veins on the left side, one high up in the supratonsillar fossa, and the other in the bottom of the fossa just above the tongue. There was no further loss of blood, and the patient made an uninterrupted recovery, leaving the hospital on the third day after the operation.

From the profuse bleeding in this case we may say with certainty that had the same measures been employed to control it here as in Case 1 the outcome would have been as serious as in the former case, if not more so.

Many reasons have been offered as to why bleeding is great in some cases and slight in others. There can be no doubt that hemorrhage is more likely to occur in older subjects, but I have been forced to ligate vessels in a number of very young children. Severe hemorrhage has also been said to occur oftener in men than women. In my own experience, however, I can find no basis for this belief.

Hemophilia has been thought in many instances to be the cause of alarming hemorrhage. While no one will dispute the seriousness of an attempt to remove the tonsils in cases in which a real hemorrhagic diathesis exists, there are but few authentic cases of postoperative tonsillar hemorrhage where real proof of hemophilia can be produced. In the 150 cases collected from the literature by Damianos and Hermann, ${ }^{4}$ only five, from the history, were thought to be hemophiles. In but two of the eight fatalities, reports of which were collected by the same authors, could this form of dyscrasia be suspected.

Among the fifty-four cases tabulated by $\mathrm{Smith}^{2}$ and Wright, ${ }^{3}$ three patients, all of whom recovered, were said by the operators to be hemophiles. I doubt whether even three patients would have recovered had they been real hemophiles. An undoubted hemophile was the patient whose case was reported by Dr. R. H. Johnston ${ }^{5}-$ a boy, aged $1 \%$, who died fourteen days after three tonsillar crypts had been cauterized with the galvanocautery, from an almost continuous bleeding starting on the ninth day.

Dr. Chevalier Jackson ${ }^{6}$ reports a case in which he saved the life of a patient after tonsil operation, per-

5. Rev. hebd. de laryngol., 1906 , xxvii, 545 . 6. Jackson, Chevalier: Ligation of External Carotid Artery 
formed by another physician, by ligation of the external carotid artery. Subsequent developments showed undoubted hemorrhagic diathesis, the patient bleeding to death from epistaxis at a later period.

I believe that in many of the so-called hemophiles the bleeding is due to a blood vessel having been opened by cutting and not securely tied. In the Vienna case a family history of bleeding had been elicited from the patient, and, had the autopsy not proved the vessel to have been cut, this could undoubtedly have been reported as a case of hemophilia.

Cutting of either pillar of the fauces has been mentioned as a frequent cause of hemorrhage; many believe this to be the most common cause. This is probably true in those cases in which operation is done with the guillotine. In the new methods by dissection, hemorrhage is always greater when muscular fibers are exposed.

In order to have a clear understanding of the method which I employ, it will be better to follow the plan of the operation as we perform it at the Hebrew Hospital. As to the method itself nothing original is claimed. We simply apply the principle used to control bleeding in all general surgical operations-namely, to catch and tie every vessel showing a tendency to bleed profusely.

The operation performed is essentially that described by Dr. 'T. Chew 'Worthington, ${ }^{7}$ with some slight modification in the technic. The tonsil is removed by dissection en masse in its capsule, with a modified Seiler septum knife, a two-pronged vulsellum being used to pull the gland out of its bed. Patients above 14, and occasionally under that age, are operated on when sit. ting under local anesthesia. A 0.25 per cent. solution of cocain in 1 to 6,000 adrenalin chlorid solution is injected into the region after the application of a 10 per cent. solution of cocain to the surface. Very little discomfort is complained of by the patient when thus anesthetized. Operations on children, and at times adults who insist on it, are done under ether anesthesia, the patient lying on the back, with the head of the table considerably lowered, so that the blood can not easily enter the larynx; 1 to 6,000 adrenalin solution is also injected before operating. The right tonsil is first removed, the tongue being depressed by an assistant. One or more large gauze sponges held in eight-inch Kelily static forceps and ligated with ordinary No. 2 ratgut or clamps are then placed in the fossa and held there gently but firmly. The anesthetist is now directed to anesthetize the patient again fully. This being accomplished, a careful inspection of the fossa is made by holding back the anterior pillar with a pillar hook. Any spurting vessel is caught at once with Jackson's hemoblack silk. While we prefer catgut in most cases because we never hear from it again, it is sometimes easier to use silk. On several occasions, however, in which silk was used in the supratonsillar fossa it became encysted and gare rise to such irritation that we were obliged to pick it out. This does not occur when it is used lower down because it sloughs off during the process of healing.

At times, in spite of much blood pouring down the center of the fossa from above, there is no spurting vesscl visible until the supratonsillar fossa is everted by means of a couple of pairs of long dressing forceps. In turning out the fosea we must not be misguided by the

7. A Simple Method of Excision of the Fauctal Tonsils, TuE Jovixat A. M. A. May 25,1907 , xlviii, 2761 . cessation of hemorrhage, for often the pressure made during this process is sulficient to close the mouth of the vessel. By lessering somewhat the pressure of the dressing forceps we have often been enabled to find the mouth of the spurting artery. It is from an artery high up in this situation, generally a branch of the descending palatine, that we have most trouble, and there is no doubt in my mind that this artery was responsible for the serious bleeding in Case 1. Ligation of the tonsillar artery has also been found necessary a number of times. Ballenger ${ }^{8}$ has found bleeding from this vessel to be more frequent than from any other, whereas Jackson ${ }^{9}$ sees the bleeding oftener from the upper vessel, as we likewise maintain. Occasionally it is also necessary to tie a vein or two of the tonsillar plexus.

All bleeding vessels having been controlled, a gauze sponge dusted with Squibb's surgical powder is packed into the fossa to control any oozing, and thus we have our field of operation absolutely free from blood for the removal of the left tonsil.

The second tonsil is removed in the same manner, and after all bleeding is controlled we remove the adenoid vegetations if their removal is called for. Here, too, we control the bleeding with a gauze sponge held firmly in the postnasal space by means of a Kelly clamp. Often no more than one-half to an ounce of blood is lost from the triple operation, and but a small proportion of this comes from the tonsils. Generally speaking, there is more primary bleeding when ether is given than when only local anesthesia is employed.

Many assert that the ligation of bleeding vessels is impossible in the small space afforded us in this region. I do not wish to imply that it is always easy to ligate vessels deep in the fossa; on the contrary, in a small mouth, when the vessel happens to be one the posterior pillar or deep down near the base of the tongue, where the bite of the forceps must necessarily be short, we frequently have to resort to a gauze packer to slip our loop over the end of the clamp. But in most instances we tie the vessels with comparative ease.

It may be argued that the ligature is not always necessary; that torsion will often suffice. Granted that this is true in a number of cases, I believe that by the use of the ligature we not only reduce primary hemorrhage to a minimum, but that we are also secured absolutely from recurrent or secondary bleeding; I have experienced such occurrences only when the vessel was not tied. In one case I was obliged to use ether anesthesia in an adult, several hours after the tonsils had been removed under cocain, in order to catch and tie the spurting artery. This could doubtless have been accomplished with little difficulty during the operation before the effects of the cocain had worn off.

An absolute necessity in catching and ligating the ressels is to have able assistants, as one assistant should evert the pillars while the other sponges and depresses the tongue, leaving both hands of the operator free to catch and tie vessels. This is one of my main reasons for no longer removing tonsils outside of the hospital.

An important point, in my opinion, is that the patient should not be removed from the operating table to his bed until all signs of bleeding have disappeared and the throat is perfectly dry. By so doing we avoid the

8. Clinical Anatomy of the Tonsil, Tr. Am. Laryng. Assn., 1906 xxviii, 121

9. Tonsillar Hemorrhage and its Surgical Treatment, Ann. Surg., December, 1907, x!vi, 821. . 
swallowing of blood by the patient in a serniconscious state, as so frequently happens after the return to bed. Casselberry ${ }^{10}$ reports the death of a boy, 3 years of age, after the removal of one tonsil, where the primary bleeding was apparently insignificant and was thought to have ceased; yet a few hours later the child was found in a hopeless condition, the blood having been swallowed. (This patient was not operated on by Dr. Casselberry, but by some other physician whose name was not mentioned.)

It is quite generally recognized that in the presence of hemorrhagic diathesis the clotting capacity of the blood is increased by the calcium salts. In the removal of the posterior turbinal ends, in a number of cases, I have operated on the one side with, and the other side without, the preliminary administration of calcium, and in nearly every case there seemed to be much less bleeding when these salts were given.

Just how great may be the effect of these preparations on tonsillar bleeding it is, of course, difficult to say with certainty, but as it is impossible to tell in what cases hemophilia may exist, it. has been my custom for a couple of years past to administer calcium, usually in the form of the lactate, for forty-eight hours prior to every tonsillectomy. One thing is certain: it can do no harm.

Regarding the injection of adrenalin preparation, there is a diversity of opinion. Some operators believe that its use predisposes to secondary bleeding. I recall no instance when the bleeding could be ascribed to the use of this agent, and it seems to me that the advantage offered during the operation, of a less bloody field with our landmarks unobscured, more than compensates for any slight tendency to secondary bleeding thought to follow its use.

'This method of controlling bleeding has been used by me for the past ten months in both private and dispensary patients, with the utmost satisfaction. During this time styptics have been given up entirely and the pressure hemostat, formerly often applied, to the great discomfort of the patient, has fallen entirely into disuse.

In conclusion I would say that many obstacles arising at times in the management of some of my cases have been easily overcome through the efficient aid of Dr. Charles Bagley, Jr., and his assistants at the Hebrew Hospital.

1622 Madison Avenue.

\section{ABSTRACT OF DISCUSSION}

ON TONSIL SYMPOSIUM (PAPERS BY DRS. ROBERTSON, MAYER, PIERCE, PACKARD, AND COHEN)

Dr. Frank C. Todd, Minneapolis: It is evident that the profession is appreciating the fact that the incomplete operation performed with the tonsillotome has now no place in modern surgery. The removal of the entire tonsil in its capsule leaving intact its bed of muscular tissue and the faucial pillars uninjured gives the best ultimate results. But if the muscle tissue is torn or otherwise materially injured or the pillars are greatly damaged, or portions of the tonsil remain to form adhesive bands between the pillars and to continue the disease process, then the results are not the best that can be secured and may even bring about such cicatricial contraction as to interfere with the normal action of the muscles thereby causing discomfort and disturbance. Yet it is evident that considerable traumatism to these structures may take place and the results be good, even though not ideal. As

10. Chicago Med. Recorder, 1893, iv, 1. throat surgeons, however, it is our duty to try to bring about ideal results and so to perfect our technic as to accomplish this end.

While the methods now in vogue differ materially, I can not help but observe that we are coming closer together and experience is bringing us to a method which will be, I believe, more or less universally adopted. A considerable experience has taught me the wislom of avoiding the use of sharp instruments and particularly scissors and the method which I am using is similar to that described by Dr. Pierce. Dr. Cohen calls attention to the fact that it is not only desirable to stop bleeding on account of the danger to life, but for the sake of losing as little blood as possible, even though that danger does not exist. Dr Cohen quotes some as having claimed that the complete removal of the tonsil in its capsule results in less hemorrhage than following tonsillotomy with the guillotine, while he states that some others claim that the loss of blood is greater. This is undoubtedly due to the difference in the technic of various operators and I believe those who have performed the operation a great deal have worked out a more bloodless method. It will be interesting to secure the testimony of operators some years later when we have determined what may be considered the best method of performing this operation.

In regard to the use of calcium salts to prevent bleeding, I herewith quote an article recently published in THE JourNaI. of the American Medical Association, entitled "Pharmacologic Fetishisms" by Wilfred N. Barton, M.D., Washington, D. C. "The salts of calcium are supposed by many physicians-perhaps a majority-to increase the coagulability of the blood. As a matter of fact, they have no influence on coagulation time (Robertson, Illman, Duncan). Nor is it quite clear from a pharmacologic standpoint why they should ever have been expected to do so. Almost all of the calcium taken internally is passed through the bowel unchanged, owing to its extreme insolubility and impermeability. Then, too, it should be remembered that there is almost never any deficiency of calcium in the adult tissues. Treating with calcium internal hemorrhages in which the coagulability of blood is not reduced seems the height of folly. The calcium ion is useless in therapeutics."

Recently it has been called to my attention that the formation of a fibrous clot could be stimulated effectively by applying gelatine and $I$ am now using it for that purpose in the nose as well as the throat. It seems to be effective but I do not feel that my experience is as yet of sufficient value to present the results at this time. One point which $I$ wish especially to emphasize, however, is that of the position of the patient during general anesthesia. To do this operation properly and quickly a good view of the field of operation is required. The positions usually utilized, with which you are familiar, do not afford so good a view as the one which I here advocate, nor have they several advantages which will become evident to you on using this position. This I have learned not alone from my own experience, but from those who have witnessed the operation done in this position. The advantage of the position is not only the good view obtained, which can also be enjoyed by other observers, but there is absolutely no danger of the blood entering the larynx and the blood does not as easily obscure the field of operation. All assistants are out of the way and the first assistant can effectively sponge the blood and hold the tongue depressor. Dr. Chevalier JAckson, Pittsburg: I think we shall all file away this morning's symposium and the discussion which has followed and study it over carefully. I question very much if there will ever be any one way of doing tonsil operations that will be followed by every one, but if we can break down that Chinese wall we have all put around ourselves with regard to the tonsil operation we can learn much. I thought 1 knew how to do the operation but two years ago I went to Fall River and saw Dr. Richards doing the work and I went home a wiser man. I found that $I$ had not been getting the tonsils out completely. I was surprised when I found how easily one could determine by feeling in the fossa whether he had cleaned it out. When my former patients return now $I$ take out the rest of the tonsils. One patient came back and I looked in the throat and said, "Why, this is one of the most 
beautiful results from the tonsil operations I have ever had." She said "Yes, after Dr. Dickinson fixed it up; he operated two months ago." I began to find out then how Dickinson did it and found that he had a good many good points in technic. We can all learn if we are willing. Every one who has seen Dr. Pierce operate knows the skilful manner in which he handles instruments. The snare he has shown is one of the best I have seen. I can heartily endorse Dr. Cohen's paper. There is no reason why we should use ice for the arrest of tonsillar henorrhage when we know that we can control it in a surgical manner. I think ligation is at times necessary, though for the smaller vessels torsion is sufficient. It is difficult of course; every thing worth doing is difficult.

In regard to Dr. Pierce's remark as to the uniqueness of my experience in ligation of the carotid. I have been also called to task by St. Clair Thompson in the same way. My position was unique for the reason that as consultant $I$ saw these cases after everything else had been tried and the patient was moribund. I ligated the external carotid in a case in which previously caustics had been used and when the siough began to separate there was oozing again and had the carotid not been tied the patient would have bled to death. Changes in the blood in typhoid fever, diphtheria, erysipelas and other diseases may bring about a temporary condition similar to hemophilia.

As to instruments, we all have our own, of course, and we work with them until to us they are the best.

Dr. F. Gurney Stubss, Chicago: I think the conclusions we will all draw from this symposium on the tonsils is that laryngology is advancing. One of the chief criticisms that has been levelled at the laryngologist is that he is somewhat provincial: that he is inclined to shut himself up in his own field ignoring the general principles of medicine and surgery. This has led the laryngologist into many errors and it is a sad commentary that at this late day, before a section on laryngology we should have to have called to our attention such a simple surgical procedure as picking up an artery with the clamp if it is bleeding. Probably the reason the tonsil operation has been brought into such bad repute is that every Tom, Dick and Harry in the medical profession has felt that the tonsillotome is all that is necessary for this operation. The papers which have been read to-day thoroughly cover the ground. It remains for each of us to work out his own technic.

We can not get away from the paper on anatomy; that is fixed. Of course, we may have an anomaly in which an artery is not where we expect it to be, but that is extremely rare. In considering the anatomy we must bear in mind that the source of disease, which is one of the indications for operation, is in the crypts and those of us who have for a number of years been shelling out the tonsil in its capsule, with the side toward the muscular tissue smooth and shiny, have been able to put a blunt probe down in the erypts and find that the bottom of these crypts is nothing more or less than this thin capsule. That is why when a tonsillotome is used and half the gland cut off the crypts go on with the disease just the same as before the operation. All that has been accomplished is to make more room in the throat. That important factor was not lost sight of in the indictions for enueleating tonsils.

As to the pathology of the tonsil, and its function, the hypothesis of Dr. Robertson appeals to me as most rational, especially as to the function of the tonsil being past at the sixth or eighth year, and if not previously inflamed tends to atrophy, the same as the adenoid.

As Dr. Jackson has just said, each one of us will probably work out a technic which varies a little from the other man's and it all depends on how familiar we become with that technic and how dextrous. Personally in the last five years $I$ have been removing the tonsil en masse in its capsule. We have a body to enucleate which is held in position by no lig. ments; it simply rests between the faucial pillars held there by a refiexion of the mucous menbrane of the throat over it. Consequently by taking a knife, it doesn't matter what kind, we can easily cut through the mucous membrane and with forceps draw the tonsil well toward the median line in the throat and as soon as we have done that we see that it is attacled only by loose connective tissue. Then with blunt dissection you go around it until you get over the line of greatest circumference. From then on it is a question of how to proceed. Some keep on using the knife claiming that when you are so far there is no use discarding the knife for another instrument. Personally I use a snare at this stage and with one contraction of the hand it shells the gland out very quickly. But, of course, that is a matter of preference. The whole operation of removing a tonsil should not take more than two or three minutes.

The question of bleeding then confronts us. In the last five or sis years I have never encountered a spurting artery which necessitated a ligature. I think, however, that we should confront the matter as a surgeon would in other conditions. When the tonsil is enucleated in the manner I have described it is easy for you to see the blood vessels of any size that are cut and they are in loose connective tissue which allows them to contract readily. For a second after the removal of the tonsil there may be a rush of blood but as a rule the snare (and that is why I prefer it) crushes the ends of these vessels. As soon as the tonsil is out I take a piece of gauze in artery forceps and hold it in the fossa for a minute and then remove it. If there should be a spurting vessel, catch it up and treat it surgically.

Dr. W. E. Casselberry, Chicago: To secure data bearing on the superiority of results in tonsillectomy, the degree of safety of ether anesthesia for this operation in children and the readiest means of controlling hemorrhage, I have collected $\mathrm{my}$ records of 610 cases of patients operated on in private practice which for comparison of results mar be divided as follows: (1) Tonsillotomy by the older methods embracing about 40 per cent. with ultimate recurrence of symptoms in one out of five cases; (2) tonsillectomy, not quite complete, in 20 per cent. with few actual recurrences but with many minor complaints from retention of secretions in the few follicles which escaped removal; (3) modern total tonsillectomy. in 40 per cent., with practical freedom from recurrence, in all cases.

Total tonsillectomy is an ordeal through which few adults are able to sit quietly for both tonsils at one time, and as the after-soreness is considerable, an interval of a week between the two is my customary recommendation excepting, of course, when a general anesthetic is given which is always necessary in young children and sometimes in adults to insure the quietude which this operation demands. When done in two sittings, it is reckoned statistically as one operation; 245 cases, nearly all of double tonsillectomy and adenectomy, most of the patients children under 14 years of age have been satisfactorily operated on under complete ether anesthesia without any fatality or other accident excepting threat. ened respiratory syncope twice which yielded promptly to artificial respiration, and without any subsequent pneumonia or nephritis or any permanent detriment. Midway during the preliminary etherization the throat is sprayed sparingly with a 2 per cent. cocain solution with adrenalin 1 to 2,000 , an expedient which accounts for a more satisfactory quietude of the throat with avoidance of delays than is commonly credited to ether. Safety is likewise promoted by a special position of the patient which, while guarding against aspiration of blood, expedites the operating by diminishing the de. lays caused by bleeding. The right abdominal position which I now use throughout for the heavier patients and in part for all patients, differs from the usual lateral position in that the patient lies, not strictly on the side, but on the abdomen and antero-lateral surface of the chest and shoulder, the right arm being drawn from below backward across the table, which prevents him from rolling off. The face is first directed upward for convenience in removing the right tonsil but at the first free flow of blood the face is rotated downward, which $\mathrm{I}$ eall the bleeding position, in which as bleeding lessens without waiting for it to stop, one can proceed unembarrassed by the blood flow, to enucleate the left tonsil, provided the operator kneels to direct a good headlight from below upward into the throat. However for smaller children who can be turned quickly and neatly I still prefer the dorsal position with head and shoulders raised, for the first tonsil, turning at the eritical moment to the bleeding position for the second tonsil and returning again to the dorsal position for the adenoid. 
Hemorrhages requiring supplementary means of control, in children, have been less than one per cent., whereas in adults all methods represented. none proving exempt, they have been 8 per cent., or if stated in terms of single adult tonsils 10 to 25 , the ratio figuring the same since the use of adrenalin as before it, and the same for tonsillectomy as for tonsillotomy; but the cleanness of the socket after total enucleation renders it easier to find a bleeding vessel. These hemorrhages were all arterial and continued from 1 to 10 hours, showing no tendency to stop till controlled by the following means: In 8 cases by galvanocauterization; in I case by actual cauteriza tion; in I case by solid silver nitrate cauterization; in 3 cases by hemostatic forceps; in 3 cases by Mikulicz' 'ompressor; in 1 case by digital compression.

DR. C. F. Welty, San Francisco: All tonsillar hemorrhage comes from remaining tonsil tissue. To describe just how this comes about, and why it is so I will have to describe the technic of the way I operate. I have stopped doing cocain operations entirely. The patient is sent to the hospital the night before, the bowels emptied and no breakfast allowed in the morning. A half hour before operation a $1 / 4$ grain mor phin with a $1 / 150$ atropin is given hypodermically; children in proportion, governed by the weight of the patient, and no morphin given to children under four years of age. The patient is placed on the back; primary anesthesia of nitrous oxid is given until they are completely under, and then ether until the patient ceases to struggle or the irritation is over. come; then the mouth gag is applied and the head drawn toward the right, the operator sitting on a chair. I have been using Dr. Rupert's cannula in the mouth. At this stage the throat is apt to be filled by mucus which is cleared away and a I to I,0no solution of adrenalin is injected into the mucous membrane around the tonsil, about $1 / 2 \mathrm{dram}$. Then with any kind of a knife the mucous membrane is severed just where it attaches to the tonsil; and this is a very important step. My assistant holds the tongue and that is all; I take care of the hemorrhage myself. I use one anatomic forceps and one nasa forceps with an acute angle. I can change my hold of the tonsil with this very easily without causing hemorrhage. This incision through the mucous membrane is all the cutting that is done. Then $I$ introduce the anatomic forceps and sweep it around and generally find that. with a single sweep the tonsil is out in the throat. Sometimes it takes longer and sometimes the adhesions must be cut. Then the snare is put on and the operation finished. There may be a rush of blood, when a sponge is put in and held there for a minute or so, being changed as soon as it is saturated with blood, and being held with considerable pressure. If the bleeding does not stop in a short time I look for the bleeding vessel and grasp it with the forceps, allowing them to remain on for a few seconds and then taking them off. If it continues to bleed I suture the pillars at once. I never allow a patient to leave the table while bleeding. I have 250 such cases to report, with one severe bleeding, and in that case the tonsil was not sufficiently removed.

Dr. George L. Richards, Fall River, Mass.: There are two types of these tonsils-the large ones which stand out in the throat, and the smaller submerged ones in which the capsule has considerable fibrous tissue running down into the tonsil. In order to get any tonsil out completely you must do the operation extracapsularly. Dr. Jackson has kindly referred to me in connection with the finger nail operation; I did not originate it. There is a point where the line of cleavage between the capsule and fossa allows the finger nail to go through. It has one ad vantage over the blunt instrument and that is that you have the sense of touch, and you can get up into the supratonsillar fossa and get the velar lobe and bring it down into the throat. As soon as the tonsil is out in the throat I apply the forceps and then detach with the tonsillotome or snare. You can operate with any type of instrument with which you are famil iar, but the main thing is to do the operation extracapsularly.

The question of tonsillotomy or tonsillectomy is not yet settled. One-third of the operators are still doing tonsillotomy, thinking the complete unnecessary. They have not studied the literature of rheumatism and kindred infections which have their portal of entry in the tonsils or they would change their minds. I agree with Dr. Welty as to hemorrhage oc- curring because of incoinplete operation, though this is by no means always the case. Robertson showed us at the New Orleans session how to get the entire tonsil out and showed then that hemorrhage was sometimes due to incomplete op. eration. But the majority of cases reported in the literature do not seem to have been due to that cause. The six cases reported by Heuking came from injury to the pillars. It may be that this is sometimes the case, and it is as apt to be due to the tonsillotomy as to the tonsillectomy operation. It is easy to cut one of the pillars longitudinally and that is the worst bleeding to stop. One advantage of the finger method is that bleeding from this point is less apt to occur.

Dr. J. F. BARNerLL, Indianapolis: I wish to subscribe to most that has been said eoncerning thorough work in tonsil dissection, but I do not believe the time has yet arrived when we should say that all tonsils should be removed by tonsillectomy. It has been said over and over again that we do not know what the function of the tonsil is, and until we do know that it has no function we should not in every case remove it in toto. In the kind of tonsil that Dr. Mayer has spoken of as the projecting tonsil it is not always necessary to remove it by dissection. I wish to defend local anesthesia for tonsil dissection. In the great majority of cases it is not necessary to subject the adult patient to general anesthesia for the purpose of total enucleation of the tonsils. With our modern means, and with modern remedies at hand, we may with local anesthesia now state to the patient that we can dissect out his tonsils without the least pain. The tonsils may immediately be dissected loose and removed together with their capsules. I do not have any one hold the tongue except the patient himself. There is a good psychic influence in this aside from the benefit you have of having every one out of the way. They may say they can not hold his tongue down, but you tell them that all others have done so and they will succeed nearly always better than any assistant could.

In regard to hemorrhage, of course everyone should be prepared to meet the emergency. I do not believe that it is always necessary to tie these vessels. Many of the vessels that spurt only slightly will check quickly and we do not hear from them again; nevertheless, I agree with Dr. Cohen that we should be surgeons and therefore prepared to do the work surgically when it is necessary.

Dr. Mark D. Stevesson, Akron, Ohio: The surgery of the tonsillar fossa, outside of the removal of mechanical obstruction, is primarily for the removal of retention spaces. There is little benefit obtained, either locally or to the general economy, if spaces remain after tonsillectomy due to pouch formation from scar contraction, or too free granulation or folds in the pillars, the harm depending on the amount of retention. To prevent pouch formation it is usually best to sacrifice the plica triangularis and sometimes a part of a very large overhanging anterior pillar. I also use a high table but I sit on a low stool. The patient lies on his side with his upper shoulder resting against a sidepiece which is placed on the table, and which comes to within a short distance of the head of the table. The patient's head is lower than the neck, and his face points downward and toward the operator so that blood or vomited matter readily runs out of the mouth. I think that in Dr. Todd's position a port of the already too small breathing space would be filled with blood. After complete enucleation of the tonsil, I find it very difficult and sometimes impossible to seize bleeding vessels with an ordinary hemostatic forceps, so I have had a forceps made pivoted with small sharp teeth on the end which readily seize the vessels in the moving pharyngeal muscles. It is slightly larger a short distance from the end than at the end, making it easier to slip the ligature down to the tissues in ligating a vessel. I do not find it difficult to ligate vessels during the operation but very difficult afterward when the patient is nervous and weak. One-half hour before operating a small dose of bromids is given to quiet patients when a local anesthetic is to be used. After removing a tonsil under general anesthesia steady pressure of gauze in the fossa usually quickly stops all bleeding. I prefer to use a knife alone or a knife and snare under general anesthesia, but under local anesthesia when it is important not to pull the tonsil which causes pain, especially that complained of in the Eustachian region, I mucb 
prefer the seissors and use three different shapes, ome curved on the flat, another on the edge, and a third especially bent to cut free the base of the tonsil which usually lies considerably below the level of the tongue, and is difficult to cut with ordinary scissors. Under a general anesthetic the finger is one of the most useful instruments but I never employ it under local anesthesia. In dissecting the pillars free, the finger also makes a useful tongue depressor, and in addition, backward pressure can sometimes be made against the tonsil so that the knife does not draw it far from its fossa which causes after pain toward the ear.

Dr. Percy Fridenterg, New York City: As to tonsillar hemorrhage, ligation of the bleeding vessel is a counsel of perfection. Undoubtedly the surgical procedure described is the best, but in some cases we can not apply that procedure as we would desire; for instance, if we are called to see a case in which bleeding has been going on for some time it is almost impossible to find the vessels and catch them up and ligate them. In a case of severe tonsillar hemorrhage, as in epistaxis, the extreme restlessness and fear, the anxiety of the patient, often attended with shock and collapse or attacks of syncope, may make it impossible to get near the bleeding point until the action of the heart has been depressed, preferably by narcotic. This alone, by quieting the patient will sometimes stop the bleeding, and may be the only way of preparing for the surgical procedure which has been advised. When you are called in haste to such a case, and see blood everywhere: the patient spitting and coughing blood, the surrounding attendants "sweating blood," it is no easy matter to ligate a torn tonsillar vessel. In these instances we have to have recourse to measures which are not all we would wish, and among these measures I would mention a good strong hypodermic of morphin and digital compression.

Dr. F. E. V. Shore, Des-Moines, Iowa: If we are to be so perfect in our surgical technie, and do these operations as surgeons would, it is surprising to me that one would diseard the knife in a portion of the operation and use the snare to complete the work. I slould as soon expect the general surgeon to use the snare in removing the appendix or for amputating a limb. It is certainly non-surgical and when the operation can be finished just as well without danger without changing the instrument, I can not see why we should not use the knife. Personally I have always used a sharp knife with a round point as sharp as it is possible to get it. It doesn't necessarily follow that I use the sharp edge at every step of the operation. As soon as I have divided the membrane, I dissect it up from the tonsil, separating the loose tissue until the tonsil is free. I do not believe it is a surgical procedure to run the finger down the throat. It is certainly not as aseptic as to use the knife which can be done just as well. I always precede the operation with the use of adrenalin.

There is one other point and that is as to the anesthetic. I must confess that I am not in harmony with the majority of the members as to the preferabie anesthetic. I have operated in about the same number of cases that Dr. Casselberry mentioned, have used chloroform and in but two cases have I had difficulty. In one of these insteald of using adrenalin I used adrin which I understand is twice as strong as adrenalin. In the other case, I used 10 per cent. solution of cocain ap. plied to the throat. Both patients were children and there was temporary collapse. In a large number of cases, the status lymphaticus spoken of is really a status anestheticus. The anesthetist is at fault. Chloroform is safe if the anesthetist is familiar with his work. I never have hemorrhage any more. The patient must be prepared as for general operation, work done by preference in early morning before the patient has partaken of food or liquids. When the chloroform is administered, the patient should be in recumbent position with same after-care. I had some very severe hemorrhages in my early operations but have had none since adopting the routine method of ligation of the spurting vessels and in adults stitching the pillars. I remove the stitches in twentyfour hours.

Dr. O. TYDINGs, Chicago: Beginning this work some years ago. I first used the guillotine, then the blunt pointed curved bistoury, and later the cautery, for the entire removal of the tonsii. In 1902 I began the use of the knife and snare. I would separate the pillars and free the tonsil from adhesion with sharp knife occasionally using a blunt dissector until I could engage the tonsil in the loop of the snare. I spoke of this method five years ago and was reminded that the blunt dissector had been used 1,000 years before. I still have occasional use of my blunt disseetor. I think Dr. Welty has struck the keynote as to the cause of hemerrhage, as our experience at the Chicage Eye, Ear, Nose and Throat Hospital shows. Dr. Stubbs, who spoke kindly of $\mathrm{my}$ knife, and I do two-thirds of the throat work at that institution; he reports no hemorrhages. I have had six cases of hemorrhage reported to me in the past seven years, three of which I saw. I did nothing in either case as the hemorrhage had been arrested before my arrival. There are many means by which we can control hemorrhage; one is by producing an artificial hyperemia, by constricting the limbs, by lowering blood pressure with an injection of morphin or anything to divert the current of blood from the parts. That all are not so easily arrested is evidenced by the following: A few weeks ago I was called up by a gentleman to know what to do for a case of hemorrhage. I told him what $\mathrm{I}$ would do but he did not heed the advice as he had succeeded without it. When a man leaves part of the tonsil and goes back after it with a punch to remove it, he is not doing clean surgical work. The cases of hemorrhages that I have been called on to treat have been other physicians' patients in whom there had been a partial removal of the tonsil. I may run across one of these severe bleeders some day, but I haven't yet; but I certainly should not feel alarmed, if I did, if I had an ordinary pair of forceps in my hand.

Dr. Oscar Wrikinson, Washington, exhibited a curved needle by which, after packing the fossæ with gauze, one could stitch the two pillars together. By putting in two or three stitches over the packed cavity one will not have any trouble in controlling the hemorrhage.

Dr. W. W. Carter, New York City: The snare is the method I usually employ in removing the tonsils. I was surprised to hear from Dr. Wright a few days ago that probably in ninetenths of the tonsils removed by the snare there were found to be, on the outside of the tonsil so removed, striated muscular fibers. I believe this is due to two things: first, failure to follow the line of cleavage between the tonsil and fossa in separating the tonsil prior to applying the snare; second, to pulling the muscular tissue into the snare loop before bringing it home. I have seen within the last six months three cases in which the proper action of the posterior pillars has been interfered with by the removal of a portion of the muscular tissue by the snare. There was regurgitation of liquids through the nose. I wish to warn, therefore, against the use of the snare when the tonsil has not been properly liberated from the surrounding tissue, and from too great traction being made on the tonsil before bringing the snare home.

As to the use of the hemostat, I believe that it has its use, but that it is one of emergency, and should be limited to the time it takes to get hold of proper forceps, needles and sutures for stopping the hemorrhage in a strictly surgical manner. The amount of traumatism following the use of the tonsillar hemostat has been observed by me on several occasions. I saw a case recently in which the cellulitis following was sufficient, I am afraid, to cause the death of the patient. The proper method for stopping hemorrhage is to ligate the bleeding vessel, and this principle should be adhered to as strictly in throat surgery as in other parts of the body.

Dr. JosePIr WrITte, Richmond, Va.: I have operated for the removal of tonsils considerably more than one thousand times and never had a fatality and have only seen twice what I considered a very dangerous hemorrhage. In one case, I had to ligate the external carotid artery; in the other digital compression for six hours stopped the bleeding. I have not met with any other annoying or dangerous hemorrhage, and if you want a perfectly dry field you have nothing to do but make digital compression on the carotid against the spinal column. Most of the cases of bad bleeding are in adults and not in children, and compression on the carotid in this way will give you a dry field. When you release the pressure you can see the bleeding point and grasp it with a hemostat and the best one I have used for this purpose is Jackson's. Most 
cases of bleeding have been assoeiated with nephritis, and the urine should be examined before operation in every case.

DR. D. J. McDonald, New York City: I wish to speak of the question of backward children. As one looks at the matter of the discussion here to-day and notes the advances being made in this new field we must come to the conclusion that whatever method we employ we should be perfect in our operation. We know that thousands of dollars are lost to the city of New York, where there are eight hundred thousand children, because of these conditions. So that it is a matter of great importance to the community at large it behooves us to stir ourselves in order to better these conditions and save the community from excessive taxation. I have followed out the line of work of Dr. Richarás, which can be done without a great surgical armamentarium. There are, of course, dangers connected with every operation. We could show that at least 40 per cent. of the troubles of childhood are due to these conditions. Let us do the work thoroughly, no matter by what method, and save the state, the nation and the child.

Dr. N. L. Wilson, Elizabeth, N. J.: I believe that any tonsil which needs to be removed should be thoroughly removed by a tonsillectomy. I have had more pain, more infection and more bleeding from tonsillectomy, but I believe that if the work is to be done at all it should be done in this thorough manner. I do not believe in giving morphin as it abolishes the reflexes which are so important. As to adrenalin, the majority of physicians $X$ find use it too strong. It should not be used in a strength of more than 1 to 7,000 or 1 to 10,000. Just as good a hemostatic effect is obtained with the weaker solution. The question of light has been to me a very serious one. At the present time I am having one constructed for me on the plan of the Todd transilluminator. Ether is my choice as a general anesthetic, cocain and adrenalin for local anesthesia. The nurse is always instructed to watch the patient, and if she observes frequent swallowing to notify the doctor to examine the throat for bleeding.

Dr. Otto Glogau, New York City: In the April number of American Medicine I called attention to the importance of nasal examination in these cases. This is often neglected. It is necessary, especially for this work of education, to tell the school inspectors to pay more attention to the nasal condition of these children, as the correction of some primary nasal defect will avoid unnecessary removal of lymphoid tissue. Tonsillectomy may be indicated in some cases in which the patient or the parents are tuberculous or rheumatic. We do not yet know perfectly the function of the tonsils. Formerly the surgeons removed the whole thyroid but they do not now. When it is known that after the age of 12 or 14 years the tissue shrinks up why should we remove it thoroughly if the only symptoms are the interference with breath. ing? In most cases a well-performed tonsillotomy will give enough relief. The chiefs themselves in the dispensaries do not do this work and it may be dangerous if the young men should perform tonsillectomies. Besides a tonsillotomy, if done lege artis, takes a very long time and can only be performed under general anesthesia. Therefore at least in dis. pensary work tonsillotomy will be the only available method.

Dr. C. M. Ronertson, Chicago: A great deal of hemorrhage is from the palatine and tonsillar arteries which are given off from the external maxillary, sometimes very close to the external carotid. There is likely to be a hemorrhage necessitating ligature, because the vessel is cut so short that the blood clot is forced out of the vessel by the pressure of the blood current.

Dr. EmIL MaYer, New York City: In regard to my own portion of the subject I tried to emphasize the fact that not every tonsil that comes to us is grist for our mill. A child who does not present symptoms of obstructed breathing and has not had any previously existing tonsillar disease should be left alone until such time as the tonsils have had a chance to atrophy or until they become enlarged sufficiently to justify an operation. I was pleased to have Dr. Pierce make a sug. gestion which I shall surely follow-that of seizing the uvula with forceps and holding it out of the way to prevent its being engaged in the snare.

That anesthesia should never be given in a physician's office is absolute and positive; death after death has been re- ported from following this proeedure. Chlorofurm is dangerous. These operations are done for the promotion of the welfare of these children and are not operations of necessity or emergency and, therefore, it is the more tragic if anything happens and we should be very cautions. In the adult both tonsils should not be removed at the same time.

In regard to the use of instruments: We have had instruments for the separation of the pillar; sharp instruments have been shown, and blunt ones, and we have seen some of the fingers: now I have something to show you which is in between these. I have taken the curved tonsil separator and had the edges serrated; with this the tonsil is readily enucleated. As to why we discard the knife at the final stage, that is a perfectly simple thing. We discard it in the lower portion be. cause we have almost enueleated the tonsil and we come to the point of greatest danger and the snare enables us to complete the operation without danger. While we do not have hemorrhage we have a bloody surface and I would like Dr. Cohen to tell us how he ties these vessels. I think it is not so simple as has been expressed. As to the statement that the chiefs of clinic allow the younger assistants to do tonsillectomies, if the gentleman will visit my own clinic he will find that this is not so. My competent assistants do that kind of work and to each man is assigned a patient to be op. erated on and there is a check on him in the punching of the card to show who has done the operation. The junior is not allowed to do it until he has had long experience and has shown by his ability to do other things his dexterity in doing the more difficult operations; it is the last thing he is given to do.

Dr. Norval H. Pierce, Chicago: Dr. Mayer has expressed my ideas so much better than I could, that there is not much left for me to say. Regarding tonsillectomy versus tonsillotomy, Chicago I believe has been the battle ground. We have had some very warm discussions there and I was, and still am, a disbeliever in the removal of the tonsils as at one time advocated by some of my colleagues, For instance, in the early days of the work a gentleman showed me some speci mens of tonsils encased in the lateral wall of the pharynx and of which he was very proud but which showed that he did not do a tonsillectomy, but a pharyngotomy; he took out pharyngeal tissue with the tonsil and not a little of it, either. I was called to see a patient after such a pharyngotomy. The patient was suffering with profound sepsis from which he recovered after a long illness and to this day he has a torti. collis. It is very important to keep within a safe distance of the muscular tissue surrounding the tonsils and $I$ think the snare does that better than any other instrument or method. not excepting dissection by the classical finger, described most beautifully by no less a gentleman than our esteemed colleagrue Celsus, who lived, as you know, some time before the present advocates of that method.

Dr. LeE CoHex, Baltimore: I should like to correct a seem. ingly prevalent, false impression that $I$ have had an unusual number of severe bleedings. In ten years, I have had about eight cases, which I considered more or less troublesome. Perhaps some other operator would not have looked on these as very severe. Only in the two cases reported have I had any great difficulty in controlling the hemorrhage. The ligature is used not only to guard against serious bleeding but to reduce the loss of blood to the minimum, so that in frail children, convalescence may be hastened. As to the difficulty in seeing the ressels in case of profuse hemorrhage. This can always be satisfactorily overcome by packing the fossa. with from two to four gauze sponges held in Kelly clamps, the pressure from which stops the bleeding for the time being. By removing one sponge at a time, beginning from below, we are enabled to inspect the fossa in sections, and thus the bleeding point can be seen with ease.

The method of tying is as follows: The hemostat being held by an assistant, a loose single loop of No. 2 catgut is tied around the shank of the forceps and slipped down to the lower end by means of the left index finger, while the other end of the catgut is held in the right hand, no part of which? necd enter the patients mouth. By bending the forceps over, or as expressed by Dr. Finney of Baltimore, by "rocking" it, the loop is pushed over the end of the hemostat, where it is 
held by the index finger, while the right hand draws the knot tightly. The clamp is now removed and the tying completed. With catgut, three loops should be used. Though incomplete removal may be the cause of severe hemorrhage, I ean not agree with Dr. Welty, that it is the sole cause. In both severe hemorrhages reported by me, the tonsils were removed completely, with capsule intact, leaving a clean, smooth fossa. As to the removal of each tonsil separately, as suggested by Dr. Mayer, this may be advisable when a great deal of blood is lost from one side. When bleeding from the one is completely controlled by the ligature, howcver, before the other is excised, I can see no need of twice incapacitating the patient. I always remove both at one sitting.

There are two minor causes, which have appealed to me: One is foul breath when nothing but decomposing tonsillar secretion can be found to account for it. Another is pain referred to the ear, but in reality due to secretion pent up in the supratonsillar fossa. Tonsillectomy promptly relieves both conditions.

\section{TRIFACIAL NEURALGIA *}

\section{FREDERIC V. HUSSEY, M.D. PROVIDENCE, R. I.}

One has only to glance over the literature covering the subject of trifacial neuralgia to realize the state of mind in which the medical profession has been in regard to the pathology and treatment of that most painful affection. It is well known that the more uncertainty there is as to the etiology and pathology of a disease the more varied is the treatment and the less uniform are the results. Rarely do we see anthing approaching specific treatment of a disease unless the inciting cause and the resulting reaction are known.

The suffering occasioned by trifacial neuralgia has been such as to have excited for years the interest of physicians in the endeavor to find some means of permanent relief. 'The treatment of the disease has varied according as the ideas of the cause and pathology have varied, and it does not seem probable that the treatment will ever be uniform until a definite knowledge of such pathology is established. It is not the purpose of this paper to present any new information on the subject as the result of original recearch, but rather to endeavor, if possible, to arrive at some definite conclusions on the nature of trifacial neuralgia from an examination of the already existing literature on the subject.

For a long time it has been known that certain constitutional states of the body can produce a neuralgia of the trigeminal nerve. This is occasionally seen in such diseases as diabetes mellitus, malaria, syphilis, exhaustion, chronic nephritis, rheumatism. gout, learl poisoning, et cetera. As long ago as 1891 Dana $^{1}$ called attention to the fact that patients suffering from trifacial neuralgia very frequently have associated with that condition one of general arteriosclerosis. This led him to believe that arteriosclerosis was the chief cause of neuralgia. This view has been supported at times by others, notably by Putnam, ${ }^{2}$ who published in 1891 ten cases in which he found an endarteritis and a general fibrosis; and by Horsley, ${ }^{3}$ who had already advanced the same idea in $188 \%$. Later, in $189 \%$, the same surgeon, in discussing the pathology of trigeminal neuralgia, stated that he had not found any more degenerative

- Read in the Section on Stomatology of the American Yedical Association, at the Sixticth Annual Session, at Atlantic City, June, 1909).

1. Nana: Med. News, New York, 1891. Jviii

2. I'un nam: Boston Med, and Surg. Jour, August, 1891.

3. Ilorsley: Tr. Odont. Society, Lond. 1887. changes than could be accounted for by the age, condition and habits of the patients.

Cushing ${ }^{4}$ admits that arteriosclerosis is a persistent condition, but asserts that it follows the neuralgia and is a result of the pain. In support of this view, he cites a case in which, before operation, the blood pressure averaged $190 \mathrm{~mm}$., rising to $200 \mathrm{~mm}$. during the paroxrsms. Since operation the average pressure has been $140 \mathrm{~mm}$. 'The condition of heightened blood pressure is brought about, he thinks, by constantly recurring afferent impulses, which, like hard work, lead to changes in the vessels. Undoubtedly the condition of arteriosclerosis can produce trifacial neuralgia, and in these cases the use of the vasodilators to the proper degree will relieve the pain. It is easily conceivable, also, that the constantly recurring paroxysms of pain can aggrarate an already existing arteriosclerosis, so that after operation an improvement will be seen in the blood pressure.

Tumors of the base of the brain, of the skull and of the Gasserian ganglion itself, may cause a neuralgia of the fifth nerve, as can also irritative conditions about the nose and mouth. Porcher, ${ }^{5}$ in 1903 , reported six cases in which the neuralgia was due to localized inflammation in the nose, antrum of Highmore or teeth. In two of the six cases, the Gasserian ganglion had alrealy been removed by well-known surgeons, with a recurrence of the pain. Both patients were cured by proper drainage of the antrum of Highmore.

In 1905 , Snow ${ }^{6}$ reported 20 cases in which the nenralgia was due to intranasal pressure or a collection of pus within some of the accessory sinuses. He said he had seen "many cases of the acute form of tic douloureux accompany a cold with sinus accumulation and pass away with abatement of the inflammation or proper drainage of the nose." Somers, ${ }^{7}$ in a paper in 1906, mentions the nose as a frequent and often unrecognizert cause, and states that hypertrophy of the turbines, especially the middle, not infrequently produces both supraorbital and infraorbital neuralgia. He also calls attention to inflammation of the frontal, ethmoidal, sphenoidal sinuses and of the antrum of Highmore, as causes of trifacial neuralgia.

In the mouth, impacted third molars, carious teeth. pulp nodules found in the pulp chamber, and decaver roots entering the antrum of Highmore and producing antrum disease, frequently bring about a neuralgia of the fifth nerve. It is also well known that mere exposure to cold or damp weather is sufficient to start up attacks in some patients.

The type of lesion induced by the foregoing causes. which are irritative in character, is probably either a degenerative one or a peripheral neuritis which may be ascending in character, and may secondarily involve the Gasserian ganglion. But the number of cases of tic douloureux coming under this division is small and there remains by far the greater majority in which no constitutional or local irritative causo can be found. This gives some grounds for thinking there may be two types of neuralgia; one in which the lesion consist. primarily of a neuritis of the peripheral branches which may be ascending in character, and another in which the primary lesion appears in the Gasscrian ganglion.

4. Cushing: Johns Hopkins Ilosp. Bull., 1907, xviii.

5. Porcher: Tr. Am. Laryngol. Assn.. 1903.

6. Snow : Tic Douloureux and Other Neuralgias from Intranasa and Accessory Sinus Pressures, New York Med. Jour., 1905, Ixxxi. 7. Somers, Lewis $S$ : Nasal Disease and Neuralgia, The JubrNAL A. M. A., 1906, Xlvii, 741 . 